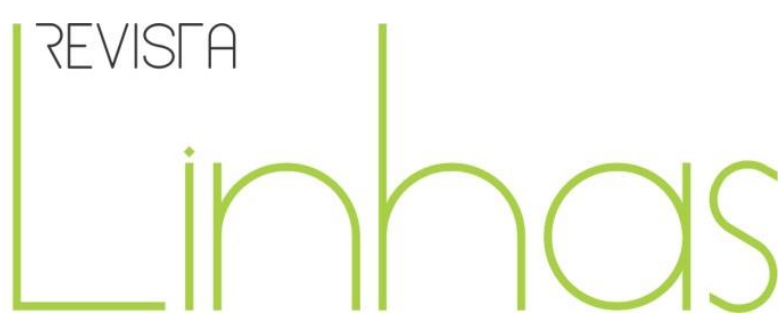

\title{
A fotografia aplicada à geografia escolar: uma proposta pedagógica de Delgado de Carvalho
}

\begin{abstract}
Resumo
O artigo analisa o uso da fotografia no ensino da Geografia a partir da perspectiva de Carlos Delgado de Carvalho. Desde os anos de 1910, esse mestre de formação francesa, adepto das teorias de Ratzel, defendia que a Geografia era uma disciplina cívica, capaz de aproximar os brasileiros do ideal de nação. Para tal, era necessário romper com os métodos de ensino de seu tempo, que se baseavam no verbalismo. Nesse sentido, defendia que a disseminação de imagens fotográficas nas salas de aula era um recurso importante para apresentar os estudantes às regiões desconhecidas do país, contribuindo para integração nacional.
\end{abstract}

Palavras-chave: Geografia; Estudo e ensino; Fotografia na educação.

\author{
Patrícia Coelho da Costa \\ Professora do Departamento de \\ Educação da Pontifícia \\ Universidade Católica do Rio de \\ Janeiro - PUC/RJ. Doutora em \\ Educação pela Universidade de \\ São Paulo - USP - Brasil \\ pcoelho@puc-rio.br
}

\section{Para citar este artigo:}

COSTA, Patrícia Coelho. A fotografia aplicada à geografia escolar: uma proposta pedagógica de Delgado de Carvalho. Revista Linhas. Florianópolis, v. 17, n. 33, p. 189-205, jan./abr. 2016.

\section{DOI: $10.5965 / 1984723817332016189$}

http://dx.doi.org/10.5965/1984723817332016189 


\title{
Photograph applied to school geography: Delgado de Carvalho's pedagogic proposal
}

\begin{abstract}
This paper analysis the use of photography in Geography teaching, from the perspective of Carlos Delgado de Carvalho. Since the years 1910, this master influenced by the French school, who was a supporter of Ratzel theories, sustained that Geography was a civic subject, able to promote the ideal of nation among Brazilian people. For such, he had to challenge the teaching methods then adopted, based on verbalism. In this sense, he ascertained that the dissemination of photographic images in classrooms appeared as a useful resource to present students to unknown regions of the country, thus contributing to the improvement of a national integration.
\end{abstract}

Keywords: Geography; Study and teaching; Photography education. 
Na década de 1910, os intelectuais acreditavam que a falta de democratização da nossa educação era o maior problema nacional e que, ao ser solucionado, todos os demais estariam resolvidos. Este discurso faz parte de um contexto maior classificado por Nagle (1976) como o entusiasmo pela educação. Carlos Delgado de Carvalho foi um destes homens. Em 1906, aos 23 anos de idade, para elaborar sua tese de doutoramento, Le Brésil Meridional; étude economique sur les états du sud: São Paulo, Paraná, Santa Catarina e Rio Grande do Sul (1910), estudou a geografia do sul e sudeste brasileiros a partir de conceitos inovadores para a época como o historicismo, em que a realidade humana é explicada a partir de sua historicidade. Como professor, defendia que a Geografia era uma disciplina pátria, fundamental ao desenvolvimento do sentimento nacional. Os métodos retrógrados aplicados ao ensino da geografia eram um empecilho a este propósito. Entre os problemas estavam a extensa lista de nomes que deveriam ser decorados, a falta de atualização dos dados sobre o nosso país e a escassez de outros recursos além do livro e da palavra do mestre. Da forma como era ensinada em nossas escolas, pouco contribuiria para formar cidadãos.

O ensino da geographia pátria é entretanto um dever de intelligencia e de patriotismo. Aos nossos jovens patrícios não devemos presentar a geographia do Brasil como uma disciplina austera e ingrata ao estudo. Por meio de bons mappas, de graphicos de perfis, de diagrammas, de photographias, si for possível, é preciso torná-la fácil e captivante. É pelo conhecimento do paiz, pela consciência de suas forças vivas que podemos chegar a apreciá-lo a seu justo valor. (DELGADO DE CARVALHO, 1913, p. X)

Ao longo deste período, durante o qual a educação passa a ser vista como uma via de atuação destes intelectuais, a reforma da sociedade aconteceria por meio da reforma do ensino. Tal reformulação deveria atingir o próprio conceito de educação e as práticas pedagógicas. Os manuais escolares apresentam marcas deste debate, uma vez que integram o rol das mudanças propostas à escola. Por sua vez, estes passam a ser elaborados no Brasil, abordando a nossa realidade, em substituição aos importados usados por nossos estudantes. 
Em 1913, Carlos Delgado Carvalho escreveu a Geographia do Brasil, manual escolar destinado ao ensino secundário. A partir do modelo proposto pelo geógrafo francês Vidal de La Blache, o livro apresentou o Brasil por uma visão que permitia agrupar, em uma mesma região, diferentes estados. O território nacional dividido em cinco regiões, ou seja, na septentrional, na nordestina, na oriental, na meridional e na central, foi analisado de acordo com as características do clima, do relevo e da hidrografia. A obra tinha como objetivo romper com a tradição do ensino da geografia baseado na memorização das características dos pontos geográficos que, por sua vez, eram estudados isoladamente. 0 autor assim justificou a opção metodológica inovadora:

A geographia tem por objecto o estudo da terra como habitat do homem. Infelizmente não é sob este ponto de vista que é estudado entre nós este ramo scientifico. Nas escolas do Brasil e de outros paizes de nosso continente, a geographia é o estudo de uma das modalidades de imaginação humana, isto é faculdade de atribuhir nomes, de chrismar áreas geographicas. As montanhas, os rios as regiões naturaes não são estudados em si, mas apenas como merecedores de um esforço de nossa fantasia. (DELGADO DE CARVALHO, 1925, p. 42)

A proposta sugeria a inserção de outras técnicas pedagógicas ao ensino da geografia como a elaboração de dissertações a partir de pesquisa bibliográfica, análise de mapas e imagens. Recomendava a utilização adequada de recursos inovadores, a saber: do atlas, dos murais, da fotografia, dos cartões-postais, das projeções fixas e das fitas cinematográficas. Neste aspecto, as imagens, em especial as advindas das fotografias, tinham papel de destaque no método. Estes recursos visuais fariam com que os alunos visualizassem, superassem a imaginação construída a partir do conhecimento memorizado. Estas seriam capazes de aproximar os brasileiros de regiões do país ainda desconhecidas, colaborando com a integração nacional.

O objetivo deste texto consiste em analisar não só proposta pedagógica elaborada por Carlos Delgado de Carvalho, mas também a inserção da fotografia ao ensino da geografia, como estratégia para aproximar os brasileiros de regiões ainda pouco conhecidas do país. As fotos passaram a ser admitidas como um recurso didático importante, que devem estar presentes no cotidiano das salas de aula, por meio dos 
livros, dos murais escolares e dos arquivos dos professores. As imagens são compreendidas como essenciais à formação de um ideal de nação para os nossos estudantes. Neste aspecto, este estudo colabora com uma compreensão sobre a história das práticas pedagógicas desta disciplina.

\section{A proposta pedagógica de Carlos Delgado de Carvalho}

Ao chegar ao Brasil em meados da década de 1900, Carlos Delgado de Carvalho encontrou um campo intelectual bem menos estruturado que o francês que havia moldado a sua formação na Escola de Ciências Políticas de Paris. Segundo Martins (1987), ainda que a intelligentsia brasileira já estivesse constituída e esta possuísse plena consciência da necessidade da reforma das instituições políticas e sociais, esse núcleo de pensadores ainda não havia encontrado um mecanismo que lhe permitisse transformar a realidade por meio da ciência. A intelligentsia "está profundamente convencida de sua contribuição a transformação das estruturas sociais, ainda que não saiba como fazê-lo. Com efeito, para realizar a tarefa que se atribui, ela só dispõe do poder das idéias" (MARTINS, 1987, p.79).

Segundo Bourdieu (1989), os intelectuais fazem parte de um campo científico que é palco de constantes disputas. Ainda que, em 1925, a geografia brasileira ainda não constituísse um ramo de conhecimento autônomo, com regras específicas que determinassem a legitimidade, o que somente viria a ocorrer na década seguinte com a criação dos primeiros cursos universitários, seus estudiosos nem por isso deixavam de inserir-se num universo intelectual. Nesta qualidade, disputavam entre si o monopólio da autoridade científica, que consiste na capacidade de falar e agir legitimamente diante deste campo.

Na década de 1920, o monopólio do conhecimento geográfico pertencia aos intelectuais ligados ao Instituto Histórico e Geográfico Brasileiro (IHGB) e à Sociedade de Geografia do Rio de Janeiro. Estes estudos tomavam por base uma ótica positivista e uma grande preocupação com a definição das nossas fronteiras. O livro de Mario Veiga Cabral, Chorographia do Brasil (1916) reflete esta linha de pensamento. Já na introdução, o autor, membro da Sociedade de Geografia do Rio de Janeiro, anuncia a sua preocupação em 
transmitir um conhecimento mais exato do nosso território, o que, segundo ele não era alcançado por outros manuais. Na extensa obra de oitocentos e cinco páginas elaborou uma detalhada descrição da superfície, dos limites, da população e das dimensões territoriais de cada estado brasileiro. Tal trabalho utiliza como fonte os estudos de Rondon, a quem o autor faz muitas reverências. Este manual, cujo retumbante sucesso editorial o fez passar, já na década de 1920 da $20^{a}$. edição, transmitia o conhecimento gerado por engenheiros, diplomatas, escritores e militares em suas viagens pelo Brasil, documentando pontos geográficos por meio de fotos, amplamente utilizadas para a ilustração de textos. Como membros da Sociedade de Geographia do Rio de Janeiro, tais profissionais figuravam como uma voz autorizada diante do campo.

Neste campo, a Geographia do Brasil (1913) de Delgado de Carvalho representou a inovação. Este manual escolar, dirigido aos estudantes do ensino secundário, e elaborado a partir de viagens do autor pelo país, analisou nosso território sob a perspectiva de Jean Bruhnes e Vidal de La Blache, orientadores do movimento denominado geografia moderna, que relacionava a análise geográfica ao homem. A obra manifestava a clara intenção de romper com a escola clássica:

É pois mais que necessário abolirmos no ensino da geografia practica tudo quanto nomenclatura tudo quanto é puramente mnetchnico para 'so encarar os factos em marcha pode-se dizer, e no seu respectivo lugar. É útil afastar-se, de vez em quando, do quadro habitual das concepções geographicas tradicionaes. Até hoje no nosso ensino, toda a idea nova, todo progresso geographico da sciencia geographica ente nos, tem sido sacrificados aos moldes natigos, tem sido apresentados, num quadro archaico: os espíritos não são levados a ver a geographia tal como ela é. (DELGADO DE CARVALHO, 1913, p. 5)

Nesta luta pela transformação dos referenciais teóricos de nossa geografia, o Colégio Pedro II exerceu um papel relevante. Padrão de ensino da época, abrigava em seu quadro de professores intelectuais de reconhecida autoridade científica. Como nos lembra Gomes (1996), tão ou talvez mais importante do que uma escola superior, o Pedro II, “era um lugar vital na sociabilidade intelectual dos que vivem no Rio de Janeiro da virada do século" (p.44). 
Para Sirinelli (1996), a sociabilidade configura um aspecto importante na formação de ideais dos intelectuais. Sentimentos como amizade, afinidade cultural, atração ou até a rivalidade e a hostilidade criam um microcosmo particular capaz de atuar na formação do pensamento. Ainda seguindo este raciocínio, o autor também nos lembra que, "todo grupo de intelectuais organiza-se também em torno de uma sensibilidade ideológica ou cultural comum e de afinidades mais difusas, mas igualmente determinantes, que fundam uma vontade e um gosto de conviver" (SIRINELLI, 1996, p.248). O grupo composto por Everardo Backheuser, Fernando Raja Gabaglia e Honório Silvestre, professores desta disciplina, e por Delgado de Carvalho professor catedrático de Inglês da mesma instituição, congregava intelectuais que compartilhavam o mesmo desejo de mudança e a mesma fundamentação teórica. As críticas destes professores aos métodos foram relembradas nos estudos de Zarur (1941, p. 514).

Para eles os compêndios tinham uma preocupação basicamente com nomenclatura dos acidentes geográficos sem uma relação entre estes: 0 ensino era ministrado em dois anos. No primeiro ensinava-se a geografia geral, quase sempre uma enumeração estéril dos nomes sem nenhum objetivo determinado senão a fazer o aluno decora-los sem procurar a explicação dos fen6omenos geográficos correspondentes entre eles.

Em substituição à descrição dos pontos geográficos, estes adeptos à chamada geografia moderna defendiam o seguinte conteúdo programático sugerido por Delgado de Carvalho:

\footnotetext{
algumas noções de demografia, elementos de etnografia, isto é distribuição de raças, línguas e religiões, princípios geraes de mesologia ou influência do meio sobre as sociedades humanas, noções de geographia política, ou feições sociológicas dos grupos com as suas resultantes phases da civilização e instituições sociais e por fim, traços de geographia econômica. (DELGADO DE CARVALHO, 1925, p. 11)
}

Como nos lembra Bourdieu (1989), o Estado enquanto instituição oficial, produz classificações oficiais, que por sua vez têm um valor de título. Tal título é concedido aos catedráticos do Colégio Pedro II, uma vez que o Estado o reconhecia como uma 
referência. Sendo estes professores uma voz autorizada diante da intelligentsia brasileira, a adoção da geografia moderna em seus programas deu grande impulso ao reconhecimento dos estudos de Delgado de Carvalho diante do campo intelectual.

A evidência mais clara sobre este processo foi o Decreto 16782 A de 13 de janeiro de 1925. Também conhecido com Reforma Rocha Vaz, tinha, dentre outros objetivos, o de reformar os ensinos secundário e superior. Em relação ao primeiro, amplia o período de duração do curso para seis anos em regime seriado, e estabelece um caráter único para todo território nacional. Desta forma os estabelecimentos que pretendessem contar com o reconhecimento oficial deveriam seguir o padrão pedagógico e administrativo do Colégio Pedro II. Logo, oficializa-se o programa de geografia em que preponderava claramente a perspectiva de Delgado de Carvalho transformando-se o paradigma da geografia escolar e legitimando este intelectual diante do campo.

Para a divulgação de sua proposta pedagógica Delgado de Carvalho elaborou a Methodologia do ensino geographico (introdução aos estudos da geographia moderna) (1925). A obra é dirigida a um público bem definido: os professores. No contexto de sua publicação, o autor deixa clara sua intenção em interferir na cultura escolar, convencendo os professores a mudarem sua prática, por ele considerada ultrapassada - por basear-se na memorização e imaginação dos pontos geográficos. Utilizando modelos franceses e ingleses de educação, prescreve aos professores novas atitudes no trato com a disciplina.

Em todo e qualquer assumpto de geographia, o meio em que vive o alumno deve ser escolhido como assumpto principal de estudo e as noções sobre outras regiões devem ser acrescentadas como informações supplementares e comparativas. A terminologia geographica, para uso didactico, deve ser expurgada de semelhantes puerilidades. (DELGADO DE CARVALHO, 1925, p. 7)

O professor é visto pelo autor como principal agente desta mudança. O mestre é representado como um autodidata, despreparado para introduzir uma perspectiva teórica ao ensino e resistente a mudanças. Diante disso, o autor os coloca como o maior obstáculo enfrentado pelo Brasil em seus esforços em alcançar o progresso. 
Um movimento análogo entre nós terá que luctar com as seguintes dificuldades: $1^{\circ}$. A falta de vulgarização dos modelos e typos do novo curso geographico, cujo conhecimento é ainda restricto a meia dúzia de estudiosos; $2^{\circ}$. A difficuldade de alcançar e reunir os professores de geographia; $3^{\circ}$. Caso seja possível alcançal-os, a difficuldade de convencelos de que o estiveram ensinando até hoje poucas relações tem com a verdadeira geografia. (DELGADO DE CARVALHO, 1925, p. 9)

A análise da Methodologia do ensino geographico (1925) nos ajuda na compreensão do método. Numa rápida introdução, Delgado de Carvalho apresenta teoricamente a proposta. Defende a antropogeographia de Ratzel como processo irreversível de humanização dos conhecimentos geográficos: "uma das novas tendências de geographia é de se tornar cada vez mais humanas nas suas investigações" (DELGADO DE CARVALHO, 1925, p.10). Em seguida, situa sua proposta para geografia escolar no amplo debate presente sobre a construção de nossa nacionalidade: "a geographia pátria precisa, por conseguinte, servir de base e de ponto de partida ao estudo da physiographia e da geologia do globo. Devemos passar mais rapidamente sobre os assumptos que não tem applicações no Brasil” (DELGADO DE CARVALHO, 1925, p.7). O autor compartilha da preocupação de outros autores em nacionalizar os conteúdos de forma a divulgar o aspectos desconhecidos do nosso país e, assim acelerar o processo de construção da nação, ainda incompleto na década de 1920.

Mais adiante, todo o livro é usado para descrever detalhadamente todas as atitudes em sala de aula. Começando pelos recursos didáticos, enumera a sua utilização organizando as etapas em itens e subitens:

1)texto

a)leitura do compêndio;

b)exposição oral na aula.

2)O atlas

a)leitura do atlas antes do uso do compêndio;

b)consulta do atlas para localizar o que diz o texto;

c)leitura do atlas para encontrar o que não diz o texto;

d)uso do atlas para a preparação schematica da lição.

3)A palavra do mestre

a) crítica da exposição oral;

b) explicação do texto e inquéritos;

c) commentarios e dados complementares ao texto; 
d) leituras geographicas;

e) orientação dos exercícios práticos.

4)A pratica

a) exercícios cartográficos;

b) exercícios estatísticos e diagramas;

c) estudo da documentação photographica; interpretação oral;

d) dissertações geographicas. Problemas

e) experimentação- laboratório de geopgraphia, medições, observações, passeios,

etc.

(DELGADO DE CARVALHO, 1925, p. 109)

Cada um destes itens deste é apresentado separadamente. Há uma apresentação do recurso, da forma de utilizá-lo, de selecioná-lo e por fim, ilustra-se o assunto com um exemplo prático. Lançando mão do recurso do grafismo para dirigir o olhar do leitor ao que considera mais importante, coloca-se em itálico, abaixo de cada um destes títulos o resumo com as principais ideias do ponto.

A escolha do formato, pequeno e leve, podendo ser facilmente transportado, revela a intenção de Delgado de Carvalho que este fosse usado como um guia, que deveria estar sempre à mão para ser consultado. Como orientação, o decálogo é um interessante recurso do autor. Nesta parte todas as prescrições são resumidas em dez normas que o bom professor deve seguir. Separado nas últimas páginas do livro, e de fácil acesso, exatamente para propiciar a oportunidade constante de consulta pelo leitor, ele apresenta cada regra de comportamento em menos de oito palavras em latim, fáceis de serem memorizadas e em itálico. Após um curto texto sobre a regra figura um conselho em destaque.

\section{A fotografia na sala de aula}

A fotografia, uma das representações da modernidade que marcaram o século XX, e encantava Delgado de Carvalho. Para ele, a evolução tecnológica era sinônimo de progresso e, bem-estar. Não por acaso nutria enorme admiração por Pereira Passos, que considerava o grande prefeito, e cuja gestão à frente do governo do Rio de Janeiro foi por ele definida como a era dos melhoramentos: 
Foi, pois uma época de grandes e profundas transformações. Para fazer da velha cidade colonial uma capital moderna foi preciso a energia do velho de setenta anos que, com sua viajada experiência, sua alta competência e seu entusiasmo de moço, levou ao fim o seu plano, à custa de um trabalho assíduo diário de muitas horas. Passos pouco reformou, na Prefeitura do Rio de Janeiro, mas decuplicou a eficiência de seus órgãos, tornando mais e rendoso o serviço e, acima de tudo, deu o exemplo de incansável trabalho, animado do mais alto espírito de justiça. (DELGADO DE CARVALHO, 1994, p. 99)

Delgado de Carvalho transpôs sua admiração por esta modernidade para a sala de aula, ao sugerir o uso da fotografia aos professores. Segundo Schapochnik (1989), ainda no final do século XIX, apenas os retratos de pessoas e famílias tirados em estúdios eram mais difundidos no Brasil. Somente no início do século $X X$, a introdução da máquina portátil assinalada pela marca Kodak ensejou novas possibilidades do uso da fotografia, que podendo ser transportada para qualquer lugar não dependia mais da figura de um profissional para registrar os momentos que se pretendesse eternizar: "Convém lembrar que se num primeiro momento esse tipo de equipamento era de acesso limitado aos indivíduos abastados que viajavam com frequência para a Europa, por volta dos anos 10 as Kodaks já estavam disponíveis no território nacional” (p. 471).

A fotografia gerou transformações nos estudos sobre geografia elaborados pela Sociedade de Geografia do Rio de Janeiro. Estes estudiosos, em sua maioria militares, engenheiros, e diplomatas, aproveitavam suas viagens para conhecer um Brasil como poucos e divulgar este conhecimento. Ainda que tivessem uma grande preocupação com a descrição dos pontos geográficos, suas pesquisas foram muito importantes para a construção de nossa identidade, apresentando o Brasil aos brasileiros. As fotos tiradas e publicadas na revista desta instituição serviram para o início desta aproximação, que de outra forma, não seria factível.

Segundo Benjamim (1994), esta aproximação é uma tendência do homem contemporâneo, visto que este sente a necessidade de possuir o objeto mais próximo possível. Por outro lado, a reprodução é cada vez mais capaz de espelhar fenômenos considerados únicos. 
Assim como Delgado de Carvalho, outros autores de compêndios como, por exemplo, Mário da Veiga Cabral (1916) também fizeram da fotografia um recurso didático. Contudo, a simples introdução da fotografia no livro não significava, para ele, a transformação do método de ensino:

Durante muito tempo, certos autores de compêndios de Geographia julgaram que para modernizar a sua obra era sufficiente incluir algumas dúzias de photographias em novas edições. Assim pensava, por exemplo, o velho Cortambert. Nem por isso tornavam-se entretanto mais amenas as suas listas de divisões administrativas. (DELGADO DE CARVALHO, 1925, p. 139)

Para Delgado de Carvalho, a fotografia figurava como um importante recurso didático juntamente com o atlas e o texto, desde que bem utilizada. Para tanto, prescreve as formas de seleção e utilização por parte dos professores.

Na escolha das fotos, chama atenção para a necessidade da originalidade. Esta deve retratar a realidade a ser estudada. Delgado de Carvalho fornece exemplos de fotos em livros que procuram maquiar a nossa realidade:

Existia e talvez ainda exista entre nós, a preocupação de mostrar cidades, edifícios pretenciosos, automóveis nas ruas, sgnaes exteriores de civilização, escondendo o carro de bois, as bestas, os transportes primitivos, tudo quanto dá um cunho original a região. Ora, esta é uma preocupação pueril que não engana senão aos que não devem ser enganados. (DELGADO DE CARVALHO, 1925, p. 140)

Assim, o autor recomenda o cuidado na seleção das fotos não apenas quanto à imagem, mas também quanto à qualidade da foto: "uma photographia mal tirada ou mal reproduzida, borrada ou sem perspectiva, occupa um logar precioso sem desempenhar o seu papel de informação. As vistas artísticas educam o bom gosto, agradam e ensinam por isso mesmo muito mais" (p.142).

Delgado de Carvalho indica aos professores que na seleção dos postais, eles deveriam tentar evitar aqueles que girassem em torno de delegacias fiscais e edifícios 
sem interesse. Esta observação nos remete a uma tendência dos postais deste período. Segundo Schapochnik (1998), o desejo de mostrar o grau de progresso e civilização fez com que uma série destes cartões tivesse como tema o Teatro Municipal, a Biblioteca Nacional, o Palácio Monroe e a Escola Nacional de Belas-Artes.

Neste sentido, a seleção de fotos nos mostra a intenção do autor de levar aos alunos a diversidade do nosso país. Assim como o homem do campo é apresentado aos habitantes da cidade, também o progresso dos grandes centros é levado aos moradores da área rural. As fotografias são formas de aproximar o Brasil dos brasileiros, figurando o livro como um instrumento para a divulgação destas imagens.

Delgado de Carvalho propõe que todos os professores devam manter seu próprio arquivo geográfico, com paisagens adequadas aos fins didáticos. Sugere que, diante da dificuldade na obtenção de fotos poderão ser usados os cartões postais. Ao estudar a veiculação deste tipo de correspondência no Brasil, Schapochnik (1998, p. 424) analisa que "os cartões-postais são como um convite à viagem, uma prenda dedicada àqueles que estão distantes". Parece ser justamente esta a intenção do autor, ou seja, promover uma viagem ao que o texto apenas descreve, motivando o aluno a buscar novas informações: "O alumno é curioso, de natureza, e não tem preguiça em geral de ler uma explicação de um desenho ou de uma vista. É, pois, indicado aproveitar este facto de ordem psychologica e procurar tirar delle o maximo partido." (DELGADO DE CARVALHO, 1925, p. 141).

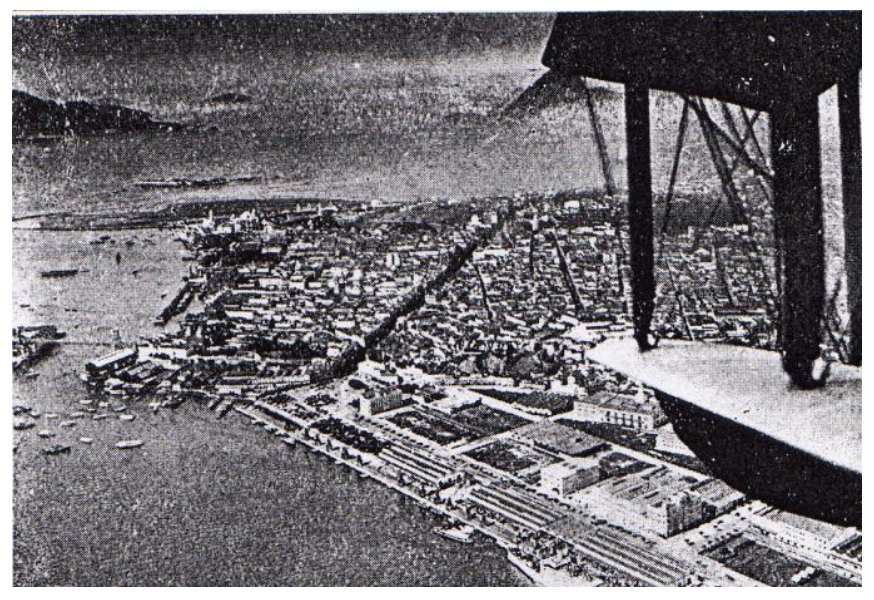

O porto do Rio de Janeiro

A parte commercial da cidade está aqui toda apanhada nesta vista tomada do aeroplano de Adyr Guimarães. O porto, ou pelo menos os últimos armazéns 16,17 e 18, estão no primeiro plano. A ponta é formada pelo morro de São Bento. A linha de sombra negra é a Avenida Rio Branco: no fundo a ilha de Villegaignon. (Delgado de Carvalho, 1928, s/p). 
Uma vez selecionada corretamente a imagem, o próximo passo ditado por Delgado de Carvalho consiste na sua utilização em sala de aula. De início, a imagem deve possuir legenda de dez ou doze linhas aproximadamente. Para Benjamin (1994, p.107), as legendas são uma forma de dirigir o olhar do espectador, "sem a qual qualquer construção fotográfica corre o risco de permanecer vaga e aproximativa". Comprovando ser esta a intenção do autor, ele cita que na ausência da legenda, o professor deveria descrever ou ditar a explicação:

Se é um rio ou uma cachoeira, aproveitar para descrever o curso d'água, lembrar a sua importância; se é uma montanha, descrever o seu typo e falar do systema a que pertence; se é uma cidade, lembrar o seu papel histórico; se é um phenomeno natural, descrevel-o ao longo. As palavras da explicação nunca são perdidas. (DELGADO CARVALHO, 1925, p. 142)

A terceira edição da Geographia do Brasil (1927) reúne todas as orientações didáticas defendidas por seu autor, a grande diferença em relação às edições anteriores é a publicação da Synthese geographica (1927), anunciada desde a primeira edição, mas só nesta publicada:

Venho tarde, é verdade, mas espero ainda poder trazer a minha contribuição à grande obra da educação nacional, cumprindo com minha promessa de 1913. Durante todos estes annos, me tenho batido pelo ensino moderno da geographia entre nós; tenho escripto e tenho falado, mas só agora me foi dado trazer a expressão do meu pensamento, em matheria de geographia pátria, dando uma forma concreta, aliás defeituosa e pallida, uma applicação tímida das idéias que venho defendendo. (DELGADO DE CARVALHO, 1927, p. IV)

A Synthese constituía um livro separado. Ao longo do texto, houve um aumento do número de mapas e tabelas com dados estatísticos para cada tópico abordado, e principalmente a inclusão de fotografias. Logo acima do índice, o nome do autor e o conteúdo correspondente ao segundo ano do Colégio Pedro II. Era uma forma de mostrar a legitimidade diante do campo intelectual. Havia um capítulo para cada região nacional, só anunciada na primeira edição. A partir da perspectiva de Ratzel, os cinco capítulos 
apresentam sempre o mesmo roteiro de estudo: descrição geral, descrição política, cidades, população e estados e, por fim, a chamada descrição especial, quando se analisam aspectos históricos da formação regional. Por fim, há três anexos. O primeiro com dados estatísticos mais atualizados, o segundo com orientação aos professores, e o último com uma série de fotos das diferentes regiões do Brasil.

\section{Geografia, a disciplina pátria}

Carlos Delgado de Carvalho fez o caminho inverso de muitos intelectuais brasileiros que sonhavam estudar na Europa. Chegou ao Brasil, em 1906, trazendo consigo um imenso capital cultural, que lhe permitiu estudar o país de uma forma inédita. Viajou pelo interior do sul e sudeste em carroças e lombos de animais. Para elaborar sua tese de doutoramento, Le Brésil Meridional; étude economique sur les états du sud: São Paulo, Paraná, Santa Catarina e Rio Grande do Sul (1910), estudou a geografia do sul e sudeste brasileiros a partir de conceitos inovadores para época como o historicismo, em que a realidade humana é explicada a partir de sua historicidade. Seguindo a mesma orientação metodológica, elaborou a Geographia do Brasil (1913) a partir das teorias de Vidal de La Blache e Jean Bruhnes, quando apresentou o Brasil dividido em cinco regiões setentrional, nordestino, oriental, meridional e central.

As obras de Delgado de Carvalho romperam com o formato descritivo como se concebia a geografia, e deram um caráter analítico ao seu estudo. Havia uma preocupação do autor que esta forma de analisar fosse incorporada ao nosso ensino. Para tal sugeria recursos visuais como a fotografia, os cartões postais, as gravuras e os mapas como alternativa a uma metodologia baseada apenas na memorização. Era preciso aproximar os brasileiros de regiões desconhecidas do país. A Geografia era compreendida como uma disciplina pátria, importante para construir o sentimento nacional.

A preocupação desse intelectual com o ensino revelam outros caminhos da institucionalização da geografia como campo científico autônomo; esse processo se desenvolveu tanto por meio do estudo de nosso território como na estruturação do ensino da geografia. 


\section{Referências}

BENJAMIN, Walter. Magia e técnica, arte e política: ensaios sobre literatura e história da cultura. São Paulo: Brasiliense, 1994.

BOURDIEU, Pierre. O poder simbólico. Rio de Janeiro/Lisboa: Bertrand Brasil/Difel, 1989.

CABRAL, Mario da Veiga. Chorographia do Brasil. Rio de Janeiro: Jacintho Ribeiro dos Santos Editor, 1916.

DELGADO DE CARVALHO, Carlos. Geographia do Brasil. Rio de Janeiro: Emp. PhotoMachanica do Brasil, 1913.

DELGADO DE CARVALHO, Carlos. Geographia do Brasil. $4^{\text {a }}$ ed. Rio de Janeiro: Francisco Alves, 1928.

DELGADO DE CARVALHO, Carlos. Methodologia do ensino geographico (introducção aos estudos da Geographia Moderna). Petrópolis, Editora Vozes, 1925.

DELGADO DE CARVALHO, Carlos. História da cidade do Rio de Janeiro. $2^{\text {a }}$. Edição. Rio de Janeiro, Secretaria Municipal de Cultura, 1994.

GOMES, Ângela de Castro. História e historiadores. Rio de Janeiro: Editora Fundação Getúlio Vargas, 1996.

MARTINS, Luciano. A gênese de uma intelligentsia: os intelectuais e a política no Brasil 1920 - 1940. Revista Brasileira de Ciências Sociais. São Paulo, n.4, v.2, p.65-87, jun 1987.

NAGLE, Jorge. Educação e sociedade na Primeira república. São Paulo: EPU; Rio de Janeiro: Fundação Nacional de Material Escolar, 1974, 1976.

SCHAPOCHNIK, Nelson. Cartões-postais, álbuns de família e ícones da intimidade.In: SEVCENKO, Nicolau. História da vida privada no Brasil. Vol.3. São Paulo: Companhia das Letras, 1998.

SIRINELLI, Jean- François. Os intelectuais. In: REMOND, René (Org.). Por uma história política. Rio de Janeiro: Editora UFRJ, 1996.

ZARUR, Jorge. A geografia no curso secundário. In: O IBGE e a Educação. Rio de Janeiro, Serviço gráfico do IBGE, 1941. Elucidário apresentado a 1 ${ }^{\mathrm{a}}$. Conferência Nacional de educação. 
Recebido em: 27/04/2014 Aprovado em: 11/12/2014

Universidade do Estado de Santa Catarina - UDESC Programa de Pós-Graduação em Educação - PPGE Revista Linhas Volume 17 - Número 33 - Ano 2016 revistalinhas@gmail.com 